\title{
Alteration of inhibitory circuits in the somatosensory cortex of Ts65Dn mice, a model for Down's syndrome
}

\author{
D. Pérez-Cremades $\cdot$ S. Hernández $\cdot$ J. M. Blasco-Ibáñez $\cdot$ \\ C. Crespo $\cdot$ J. Nacher $\cdot$ E. Varea
}

Received: 17 September 2009/ Accepted: 27 January 2010/Published online: 16 February 2010

(C) Springer-Verlag 2010

\begin{abstract}
Down's syndrome (DS), with an incidence of one in 800 live births, is the most common genetic disorder associated with mental retardation. This trisomy on chromosome 21 induces a variable phenotype in which the only common feature is the presence of mental retardation. The neural mechanisms underlying mental retardation might include defects in the formation of neuronal networks and neural plasticity. DS patients have alterations in the morphology, the density and the distribution of dendritic spines in the pyramidal neurons of the cortex. Our hypothesis is that the deficits in dendritic arborization observed in the principal neurons of DS patients and Ts65Dn mice (a model for DS that mimics most of the structural alterations observed in humans) may be mediated to some extent by changes in their inhibitory inputs. Different types of interneurons control different types of inhibition. Therefore, to understand well the changes in inhibition in DS, it is necessary to study the different types of interneurons separately. We have studied the expression of synaptophysin, Glutamic acid decarboxylase-67 (GAD-67) and calcium-binding protein-expressing cells in the primary somatosensory cortex of 4-5 month old Ts65Dn mice. We have observed an increment of GAD67 immunoreactivity that is related mainly to an increment of calretinin-immunoreactive cells and among them the ones with bipolar morphology. Since there is a propensity for epilepsy in DS patients, this increase in interneurons might reflect an attempt by the system to block overexcitation rather than an increment in total inhibition and could explain the
\end{abstract}

D. Pérez-Cremades · S. Hernández · J. M. Blasco-Ibáñez ·

C. Crespo $\cdot$ J. Nacher $\cdot$ E. Varea $(\bowtie)$

Department of Cell Biology, University of Valencia,

Dr Moliner Street, 50, 46100 Burjassot, Valencia, Spain

e-mail: emilio.varea@uv.es deficit in interneurons and principal cells observed in elderly DS patients.

Keywords Interneurons - Ts65Dn · Down syndrome · Calretinin · Parvalbumin $\cdot$ Calbindin D-28k

\section{Introduction}

Down's syndrome (DS), with an incidence of one in 800 live births (Roizen and Patterson 2003), is one of the most common genetic disorders. Trisomy on the chromosome 21 induces a variable phenotype that may include immune deficiencies, heart defects, increased risk of leukaemia and early development of Alzheimer's disease. However, the only common feature among all DS individuals is the presence of mental retardation. The neural mechanisms underlying this retardation may include defects in the formation of neuronal networks, information processing and brain plasticity. Dendritic abnormalities in DS are an index of major neuronal disruption. Changes in dendritic architecture correlate to some extent with the cognitive profile (Dierssen and Ramakers 2006).

Several models are available to mimic the alterations in DS. The most used is the Ts65Dn mouse. This model is segmentally trisomic for a portion of the mouse chromosome 16 that is orthologous to the long arm of the human chromosome 21 . This segment contains approximately 140 genes, many of which are highly conserved between mice and humans (Gardiner et al. 2003). These mice display delays in the acquisition of a number of sensory and motor tasks (Holtzman et al. 1996; Costa et al. 1999), as well as defects in learning and in the execution of memory tasks mediated by the hippocampus (Reeves et al. 1995; Escorihuela et al. 1995, 1998; Holtzman et al. 1996). 
Several studies have pointed out the possibility of alterations in the number and distribution of synapses in DS patients and in murine models. A reduction in the number of asymmetric (excitatory) synapses per neuron has been shown in the different regions of the hippocampus, as well as in the temporal cortex of Ts65Dn mice (Kurt et al. 2000). Moreover, the area occupied by synaptophysin (a reliable marker for synapses (Eastwood and Harrison 2001; Masliah et al. 1990) is higher in these mice when compared with the euploids, suggesting an increase in the size of the synapse (Belichenko et al. 2004). Finally, there is a clear redistribution of the inhibitory contacts on the dendrites of these mice: there is an increase in the density of contacts on spines and a decrease of those on dendritic shafts (Belichenko et al. 2004). Altogether, these results suggest an unbalanced level of inhibitory and excitatory inputs in the neocortex and the hippocampus in DS. Supporting this fact, an overactivation of the inhibitory system causing a general inhibition in the brain has been observed in Ts65Dn mice (Fernandez et al. 2007). This increased inhibition may be responsible, at least to some extent, for the cognitive impairment observed in DS. In fact, some studies have attempted to reverse the cognitive impairments observed in Ts65Dn mice by using $\mathrm{GABA}_{\mathrm{A}}$ receptor antagonists (Fernandez et al. 2007), obtaining promising results.

Many studies have shown deficits in the dendritic arborisation of the principal cells of the neocortex of DS patients (Marin-Padilla 1976; Becker et al. 1986; Vuksic et al. 2002). Similar results have been observed in the Ts65Dn mouse model (Takashima et al. 1981, 1989; Kaufmann and Moser 2000; Dierssen et al. 2003). The dendritic atrophy could be related to the increased inhibition observed in the patients and models of DS.

Our hypothesis is that the deficits in dendritic arborization observed in the principal neurons of Neocortex of DS individuals and Ts65Dn mice could be mediated by changes in their inhibitory inputs. Cortical interneurons can be divided into different subpopulations defined by their immunochemical characteristics such as the expression of the calcium-binding proteins calretinin, parvalbumin and calbindin D-28k. Post-mortem studies in individuals with DS reveal a reduction in the number of calbindin D-28k and parvalbumin interneurons in elderly individuals (Kobayashi et al. 1990) as well as a general reduction in the number of interneurons in Layer II and IV (Ross et al. 1984).

The Ts65Dn mouse displays a reduction in the number of calbindin D-28k-expressing neurons of the hippocampus as well as in the intensity of the calbindin D-28k immunoreactivity in the neuropil in the hippocampus. By contrast, the number of calretinin- and parvalbumin-expressing interneurons in the hippocampus are unaltered (Hunter et al. 2004), but the effect in the neocortex is totally unknown.
We analysed the distribution of the different subpopulations of interneurons in the primary somatosensory cortex of Ts65Dn mice in order to analyse possible alterations in their inhibitory pathways. We chose this region because previous studies have described alterations in their principal neurons (Dierssen et al. 2003). We have quantified the expression of synaptic markers in the neuropil and the number of total interneurons (GAD-67 expressing cells) as well as the number of calbindin D-28k, parvalbumin-, and calretinin-expressing interneurons in the somatosensory cortex of Ts65Dn mice.

\section{Materials and methods}

Experimental mice were generated by repeated backcrossing of Ts65Dn females to C57/6Ei $\times \mathrm{C} 3 \mathrm{H} / \mathrm{HeSnJ}$ (B6EiC3) F1 hybrid males. The parental generation was obtained from the research colony of Jackson Laboratory. Euploid littermates of Ts65Dn mice served as controls. For this study we used four- to five-month-old male mice ( 9 trisomic mice and 12 euploid mice).

Animals were transcardially perfused using a solution containing paraformaldehyde $4 \%$ in $\mathrm{PB}(0.1 \mathrm{M}, \mathrm{pH} 7.4)$. Brains were removed and cryoprotected using sucrose $30 \%$. Fifty microns sections (10 subseries for each brain) were obtained using a sliding freezing microtome.

\section{Immunohistochemical procedure}

Tissue was processed "free-floating" for immunohistochemistry as follows. Briefly, sections were incubated with $10 \%$ methanol, $3 \% \mathrm{H}_{2} \mathrm{O}_{2}$ in phosphate buffered saline (PBS) for 10 min to block endogenous peroxidase activity. After this, sections were treated for $1 \mathrm{~h}$ with $5 \%$ normal donkey serum (NDS) (Jackson ImmunoResearch Laboratories, West Grove, PA, USA) in PBS with $0.2 \%$ TritonX100 (Sigma-Aldrich, St Louis, MO, USA) and were incubated overnight at room temperature either in monoclonal mouse anti-synaptophysin (1:200; Sigma-Aldrich), polyclonal rabbit anti-GAD-67 (1:1,000, Chemicon Int. Inc., Temecula, CA, USA), monoclonal mouse anti-GAD67 (1:500, Chemicon Int. Inc., Temecula, CA, USA), polyclonal rabbit anti-calbindin D-28k (1:2,000, SWANT, Bellinzona, Switzerland), polyclonal rabbit anti-parvalbumin $(1: 2,000$, SWANT, Bellinzona, Switzerland) or polyclonal rabbit anti-calretinin (1:2,000, SWANT, Bellinzona, Switzerland) antibodies. After washing, sections were incubated for $2 \mathrm{~h}$ with donkey anti-mouse IgG or donkey anti-rabbit $\operatorname{IgG}$ biotinylated antibodies (1:250; Jackson ImmunoResearch Laboratories, West Grove, PA, USA), followed by avidin-biotin-peroxidase complex (ABC; Vector Laboratories, Peterborough, UK) for $30 \mathrm{~min}$ in PBS 
containing $0.2 \%$ Triton-X-100, and 3\% NDS was used for primary and secondary antibodies' dilutions. Colour development was achieved by incubating with $0.05 \% 3,3^{\prime}$ diaminobenzidine tetrahydrochloride (Sigma-Aldrich) and $0.033 \%$ hydrogen peroxide in PB for $4 \mathrm{~min}$.

The antibodies had been previously tested in their laboratory of origin; also they showed a regional and cellular immunolabelling similar to previous descriptions of these antigens. In order to confirm that some of the immunostaining was not produced by the secondary antibodies or by the immunocytochemical protocol, we omitted primary antibodies or substituted them by normal donkey serum. These controls resulted in a complete absence of immunostaining in every case.

\section{Density of synaptic markers in the neuropil}

We have analysed the intensity of the staining for synaptophysin (total synapses) and GAD-67 (inhibitory synapses) in three sections per animal corresponding to the somatosensory cortex. In order to analyse the staining we used a previously described methodology (Varea et al. 2007). Sections were examined with an Olympus CX41 microscope under bright-field illumination, homogeneously lighted and digitalized using a CCD camera. Photographs were taken at $20 \times$ magnification. Grey levels were measured using Image $\mathbf{J}$ software $(\mathrm{NIH})$. Means were determined for each experimental group (Ts65Dn vs. euploid littermates) and data were statistically analysed using the SPSS software package (version 15). The differences between groups have been analysed with repeated measure ANOVA and post-hoc tests.

\section{Density of inhibitory neurons in Ts65Dn}

We have analysed changes in the distribution of GABAergic interneurons (using immunohistochemistry for GAD-67) and of specific subpopulations (using immunohistochemistry against calbindin D-28k, calretinin and parvalbumin) in the Ts65Dn mice, and in their euploid littermates. We counted the number of immunoreactive cells found in 500- $\mu$ m-wide strips (20 strips per group) running perpendicular to the pial surface including all the layers of the primary somatosensory cortex. Also we considered number of cells in every layer (Berbel et al. 1996). After measuring the extension of the different layers, we calculated the cellular density in every layer and in the total somatosensory cortex. Means were determined for each experimental group and data were statistically analysed using the SPSS software package (version 15). The difference between groups was analysed with repeated measure ANOVA and post-hoc tests. Nissl-stained sections adjacent to the ones measured were used to determine the location of cortical layers.

\section{Results}

Expression of synaptic markers in the neuropil of the somatosensory cortex

\section{Synaptophysin}

The analysis of synaptophysin immunoreactivity showed a punctate appearance in the neuropil, whereas cell somata were devoid of staining. The immunostaining was more intense in the superficial layers than the deep ones. There is a thin strip of lighter labelling in Layer IV (Fig. 1b-e). In trisomic mice, we observed higher levels of synaptophysin expression when compared with their euploid littermates, especially in the superficial layers of the somatosensory cortex (Fig. 1a). These differences were statistically significant for Layers I, II and III $(P<0.05)$. These results were in accordance with previous data obtained in other cortical areas in this DS model (Belichenko et al. 2004).

\section{Glutamic acid decarboxylase-67}

The immunoreactivity revealed a diffuse pattern of staining, showing higher intensity in the superficial layers. Of the two antibodies used for the study of GAD-67 expression, the polyclonal one labels cell somata poorly; therefore the presence of cell bodies is quite scarce. The fine analysis of the immunolabelling revealed a punctate staining, similar to that observed for synaptophysin (Fig. 1g-j). TS65Dn mice displayed a higher expression (statistically significant) of GAD-67 in the neuropil of all layers with the exception of Layer I (Fig. 1f).

\section{Interneuron distribution}

We analysed the density and distribution of inhibitory neurons in the primary somatosensory cortex of Ts65Dn mice. Inhibitory neurons were widely distributed all over the somatosensory cortex (Fig. 2). There was a higher density in Layer III, but neurons were abundant in all layers except in Layer I. As a general trend, we observed an increment in the density of interneurons in the whole somatosensory cortex of trisomic mice $(6848 \pm 544$ cells/ $\mathrm{mm}^{3}$ vs. $5048 \pm 349$ cells $/ \mathrm{mm}^{3}, P<0.05$ ) (Fig. 2a). The study of the expression per layer revealed a statistically significant increment in the number of interneurons in Layers III, IV, V and VI (Fig. 2b). 
Fig. 1 Neuropil

immunostaining. Changes in synaptophysin and GAD67 IR in the somatosensory cortex of the Ts65Dn mice. Diagram showing changes in the expression of synaptophysin in the different layers of the somatosensory cortex in euploid (black bar) and Ts65Dn mice (white bar) (a). Example of the expression of synaptophysin in Layer II (b, c) and Layer V (d, e) in euploid (b, d) and Ts65Dn mice (c, e). Diagram showing changes in the expression of GAD-67 in the different layers of the somatosensory cortex in euploid (black bar) and Ts65Dn mice (white bar) (a). Example of the expression of GAD-67 in Layer II (b, c) and Layer V (d, e) in euploid $(\mathbf{b}, \mathbf{d})$ and Ts65Dn mice (c, e). Scale bar $25 \mu \mathrm{m}$ $(* P<0.05 ; * * P<0.01)$
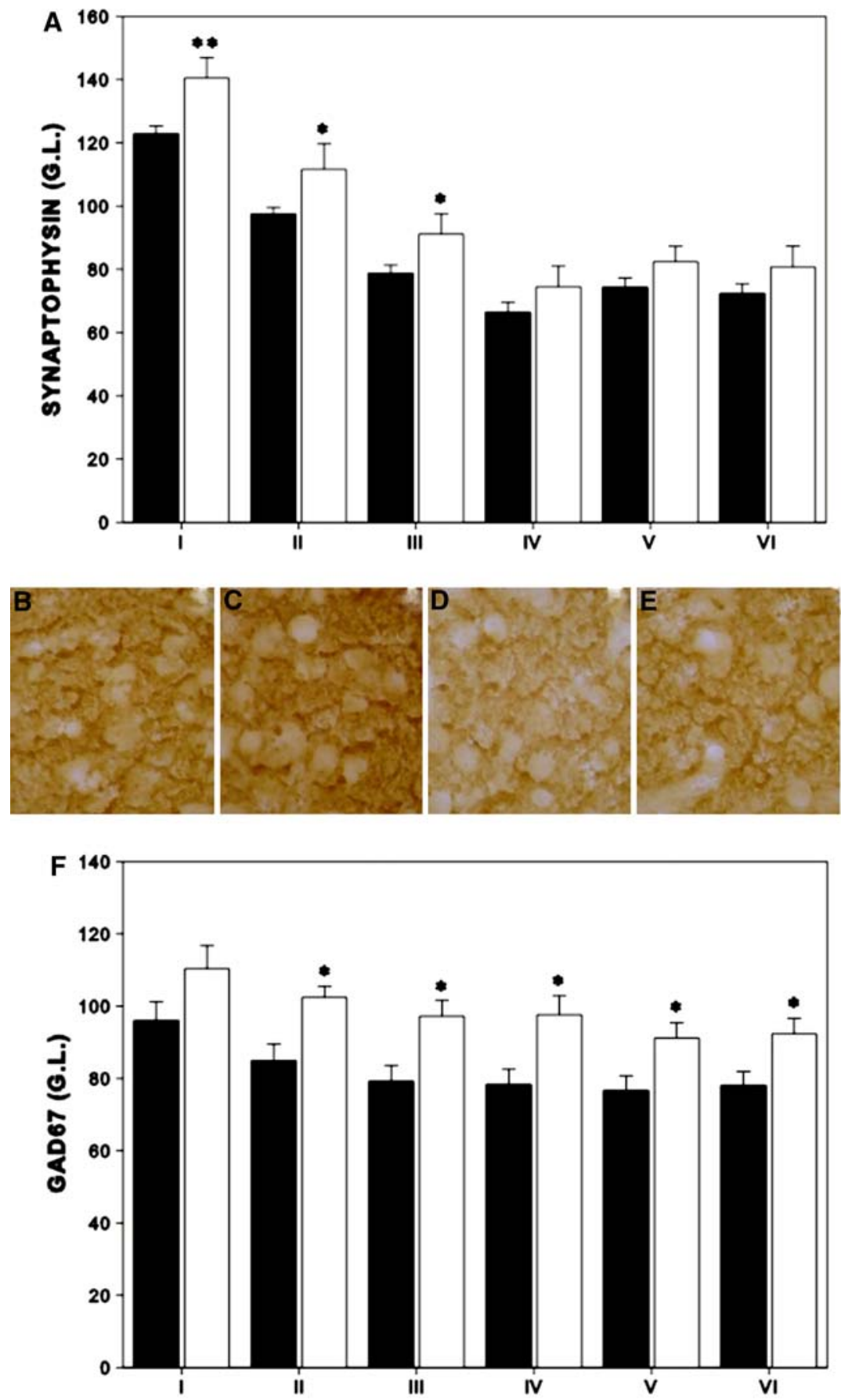
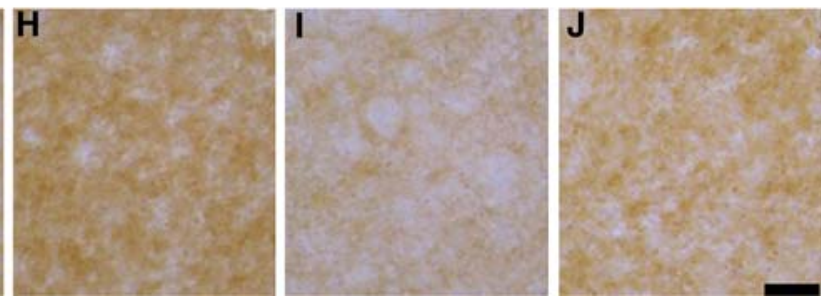
Fig. 2 Alterations in the density and distribution of total interneurons (GAD67 IR) in the somatosensory cortex of the Ts65Dn mice. a Graph showing the total density of interneurons in the primary somatosensory cortex of euploid (black bar) and Ts65Dn mice (white bar). b Graph showing the density of interneurons in every layer of the primary somatosensory cortex in euploid and Ts65Dn mice. Field survey of the somatosensory cortex of a control (c) and a Ts65Dn mouse (d), showing the distribution of total interneurons. Scale bar $200 \mu \mathrm{m}(* P<0.05$;

$* * P<0.01)$
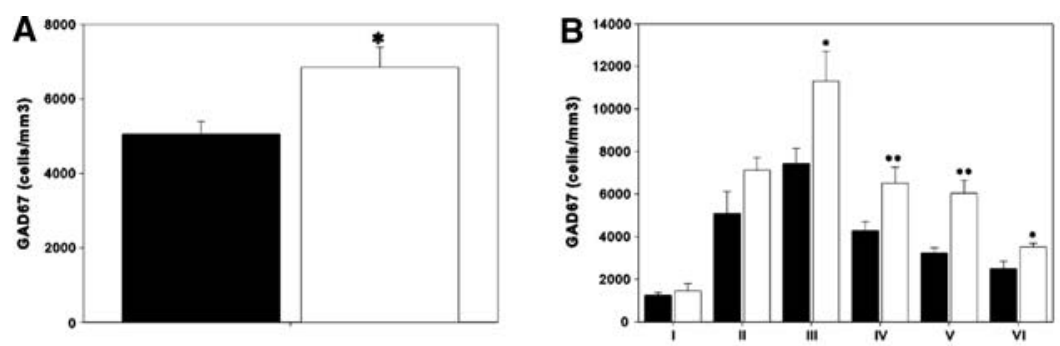

C

D

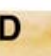

Ts65Dn
Next, we analysed if the changes in the number of GABAergic neurons were due to a change in a specific subpopulation of interneurons, for which we analysed the expression of calcium-binding proteins (calbindin D-28k, parvalbumin and calretinin).

Calbindin D-28k-immunoreactive neurons were distributed all over the layers excepting layer I, but they were most abundant in the deeper layers (V-VI) (Fig. 3). The analysis of calbindin D-28k expression revealed a slight increase in the number of neurons in the somatosensory cortex of Ts65Dn $\left(849 \pm 74\right.$ cells $/ \mathrm{mm}^{3}$ vs. $776 \pm 81$ cells/ $\mathrm{mm}^{3}$, n.s.) (Fig. 3a). A more detailed study revealed that the increase was specific to layer VI, where it was statistically significant $\left(1881 \pm 229\right.$ cells $/ \mathrm{mm}^{3}$ vs. $1213 \pm 213$ cells $/ \mathrm{mm}^{3}, P<0.05$ ) (Fig. 3b).

Neurons expressing parvalbumin were more abundant than those expressing calbindin D-28k. The study of their distribution revealed that they were abundant in layers III to V whereas layer I was almost devoid of them (Fig. 4). The analysis of the parvalbumin expression also revealed a slight increase in the total density of neurons in the whole somatosensory cortex of Ts65Dn mice $(1691 \pm 98$ cells/ $\mathrm{mm}^{3}$ vs. $1361 \pm 143$ cells $/ \mathrm{mm}^{3}, P=0,105$; n. s.) (Fig. $4 \mathrm{a}$ ). This increase was more evident in layers IV and V. Layer IV displayed the highest increment $\left(1560 \pm 87 \mathrm{cells} / \mathrm{mm}^{3}\right.$ vs. $1079 \pm 108$ cells $\left./ \mathrm{mm}^{3}, P<0.01\right)$; layer V also displayed a high increase in the density of parvalbumin immunoreactive neurons $\left(3582 \pm 143\right.$ cells $/ \mathrm{mm}^{3}$ vs. $2929 \pm 234$ cells $/ \mathrm{mm}^{3}$, $P<0.05)$ (Fig. 4b).

Finally, the interneurons expressing calretinin were as abundant as the ones expressing calbindin D-28k, but they were mainly located in the superficial and middle layers (I-IV) (Fig. 5). The analysis of the number of calretininexpressing interneurons revealed that this subpopulation was the most affected in this model. Ts65Dn mice displayed a higher density of calretinin-immunoreactive 
Fig. 3 Alterations in the density and distribution of calbindin D-28k-

immunoreactive interneurons (CB IR) in the somatosensory cortex of the Ts65Dn mice. a Graph showing the total density of calbindin D-28kimmunoreactive interneurons in the primary somatosensory cortex of euploid (black bar) and Ts65Dn mice (white bar). b Graph showing the density of calbindin D-28k-

immunoreactive interneurons in every layer of the primary somatosensory cortex in euploid and Ts65Dn mice. Field survey of the somatosensory cortex of a control (c) and a Ts65Dn (d), showing the distribution of calbindin D-28kimmunoreactive interneurons. Scale bar $200 \mu \mathrm{m}(* P<0.05)$
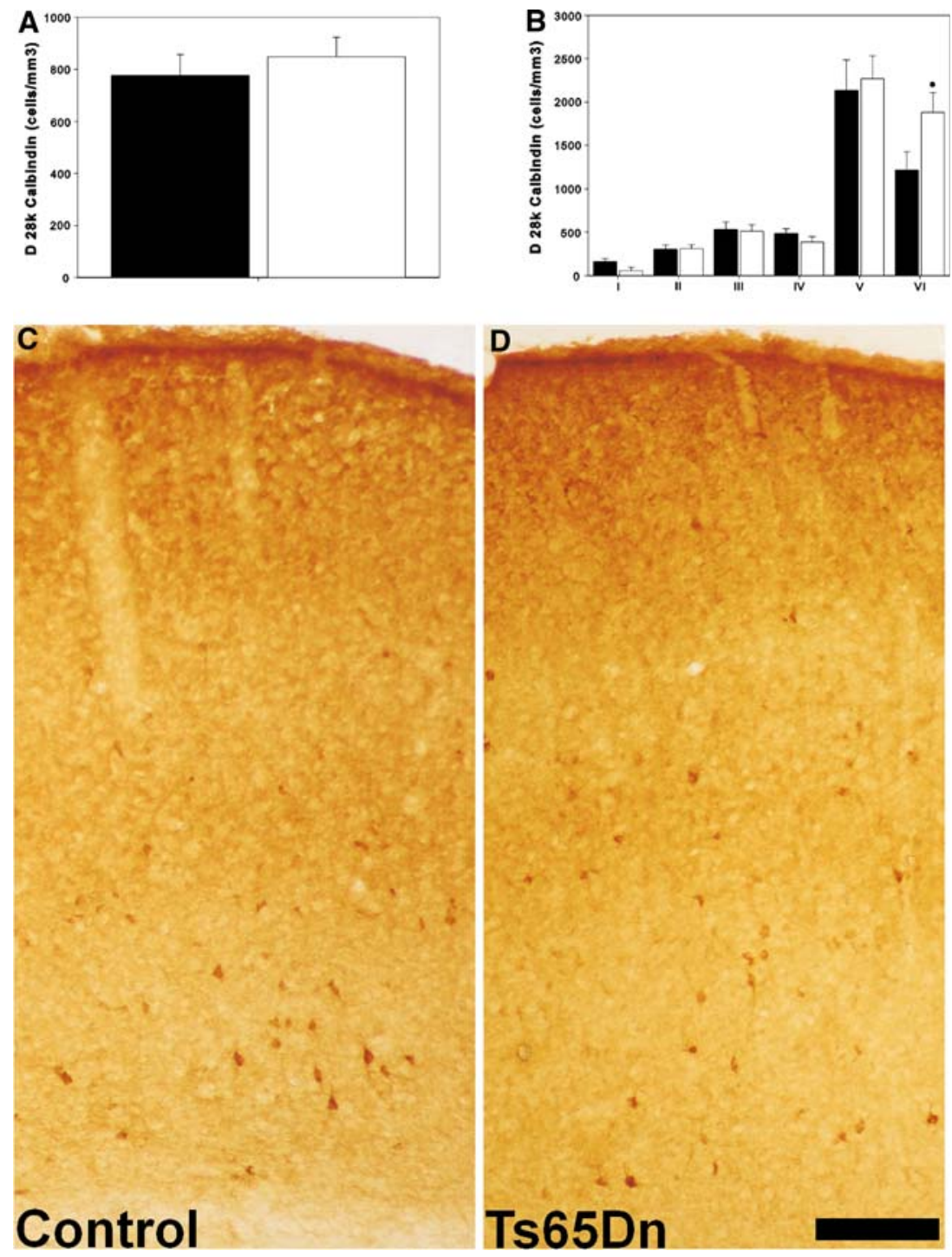

neurons in the somatosensory cortex as a whole $(1515 \pm 87$ cells $/ \mathrm{mm}^{3}$ vs. $1005 \pm 91$ cells $/ \mathrm{mm}^{3}, P<0.01$ ) (Fig. 5a). The detailed study of calretinin density in each layer of the somatosensory cortex revealed that the increment was only statistically significant in layers III and IV. Layer III displayed almost double density of calretinin-immunoreactive neurons in Ts65Dn mice when compared with controls $\left(2910 \pm 190\right.$ cells $/ \mathrm{mm}^{3}$ vs. $1663 \pm 199$ cells $/ \mathrm{mm}^{3}$, $P<0.001)$. Layer IV also displayed a higher density of calretinin-immunoreactive neurons in Ts65Dn mice $\left(1443 \pm 73\right.$ cells $/ \mathrm{mm}^{3}$ vs. $987 \pm 80$ cells $\left./ \mathrm{mm}^{3}, P<0.01\right)$ (Fig. 5b).

Two main morphological types of calretinin-immunoreactive neurons have been described in the neocortex (bipolar-BCR and multipolar-MCR). We have analysed separately the possible alteration of these populations in the Ts65Dn mice. BCR (Fig. 6a) represent around one-third of the calretinin-expressing interneurons. Ts65Dn mice displayed a clear increment of BCR in the primary somatosensory cortex $\left(550 \pm 39\right.$ cells $/ \mathrm{mm}^{3}$ vs. $299 \pm 32$ cells $/ \mathrm{mm}^{3}, P<0.01$ ) (Fig. 6c). The detailed study of BCR density in each layer of the somatosensory cortex revealed that the increment was statistically significant for layer III $\left(1079 \pm 67\right.$ cells $/ \mathrm{mm}^{3}$ vs. $512 \pm 73$ cells $/ \mathrm{mm}^{3}, P<0.001$ ) (Fig. 6e). The MCR interneurons (Fig. 6b) represented around two-thirds of the amount of CR interneurons. Ts65Dn mice displayed an increase of MCR in the primary somatosensory cortex $(965 \pm 68$ cells $/ \mathrm{mm}^{3}$ vs. $706 \pm 73$ cells $\left./ \mathrm{mm}^{3}, P<0.05\right)$ (Fig. 6d). The detailed study of MCR density in each layer of the somatosensory cortex revealed that the increment was statistically significant only for layer III $\left(1831 \pm 169\right.$ cells $/ \mathrm{mm}^{3} \quad$ vs. $1151 \pm 152$ cells $/ \mathrm{mm}^{3}$, $P<0.05$ ) (Fig. 6f). 
Fig. 4 Alterations in the density and distribution of parvalbumin-immunoreactive interneurons (PV IR) in the somatosensory cortex of Ts65Dn mice. a Graph showing the total density of parvalbumin-immunoreactive interneurons in the primary somatosensory cortex of euploid (black bar) and Ts65Dn mice (white bar). b. Graph showing the density of parvalbuminimmunoreactive interneurons in every layer of the primary somatosensory cortex in euploid and Ts65Dn mice. Field survey of the somatosensory cortex of a control (c) and a Ts65Dn (d), showing the distribution of parvalbumin-immunoreactive interneurons. Scale bar $200 \mu \mathrm{m}$ $(* P<0.05 ; * * P<0.01)$
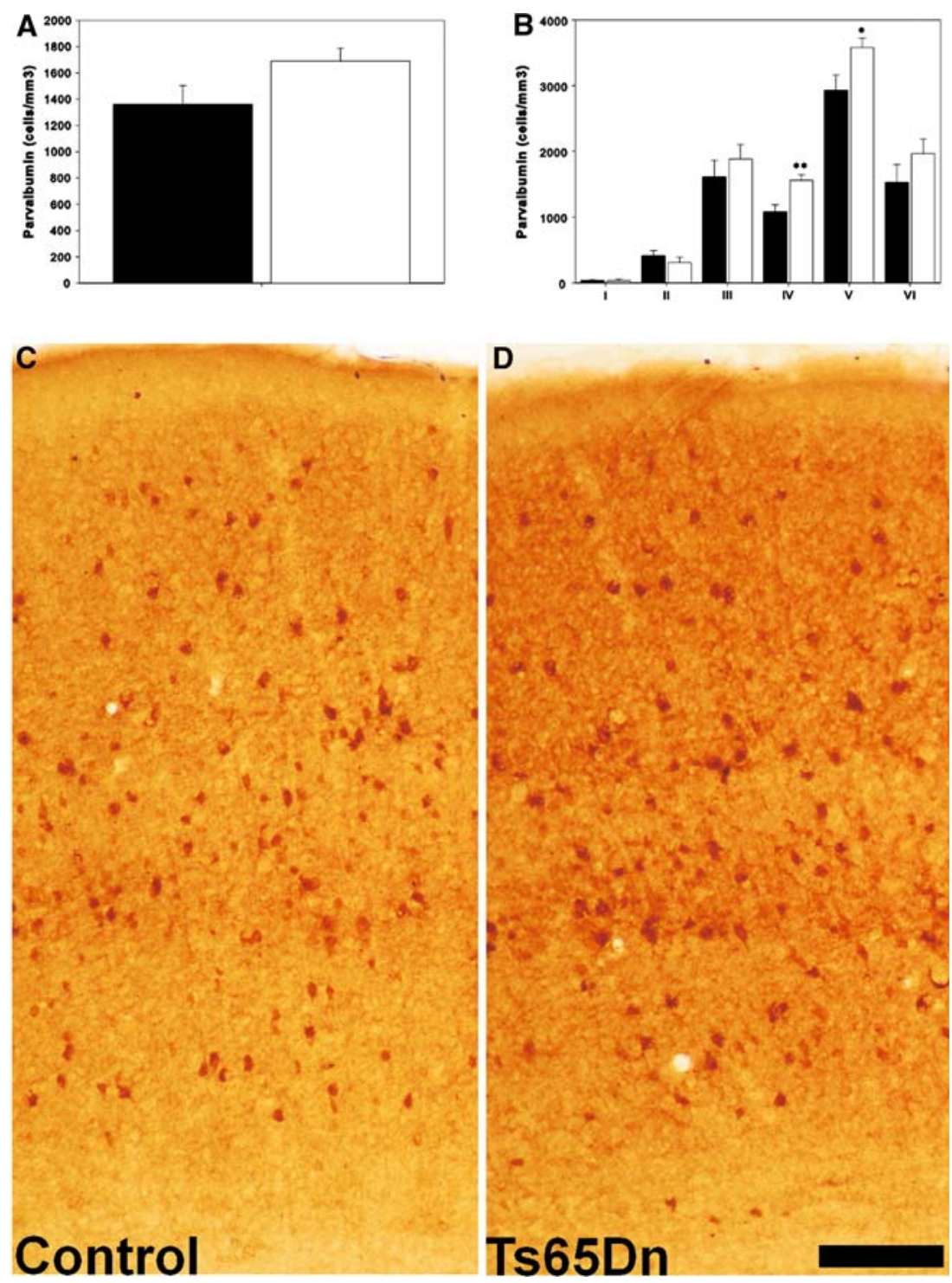

\section{Discussion}

This study reveals an alteration of the inhibitory pathways in the primary somatosensory cortex in Ts65Dn mice; this cortical region presented a higher density of total inhibitory neurons than in their euploid littermates. All the different subpopulations of interneurons investigated in the present study, using immunohistochemistry for the different calcium-binding proteins, were more abundant in Ts65Dn mice than in controls. However, the increment was especially relevant for calretinin-expressing cells and among them the ones that displayed a bipolar morphology. These alterations in the number of cortical interneurons can influence the normal function of inhibitory circuits and may underlie the cognitive deficits observed in different pathologies, including DS. In fact, changes in the relative proportions of different interneuron subtypes can cause significant alterations in the properties of a modelled neuronal network (Foldy et al. 2004).

There are several possibilities to explain that increase. It could be due to an increased survival of calretininexpressing interneurons, or to changes in their migration, integration and development. The source of calretininimmunoreactive interneurons is different from that of other interneurons (Xu et al. 2003). Previous studies have failed to label calretinin-expressing neurons by fate-mapping cortical cells that derived from the medial ganglionar eminence in vivo (Wichterle et al. 2001; Anderson et al. 2002), suggesting that these cells derived from a different place or were produced at a different time during development. Calretinin-expressing bipolar interneurons could even originate from the cortex itself. Recent evidence from explants of human embryos suggests that a substantial number of cortical interneurons arise from the cortical 
Fig. 5 Alterations in the density and distribution of calretinin immunoreactive interneurons (CR IR) in the somatosensory cortex of Ts65Dn mice. a Graph showing the total density of calretininimmunoreactive interneurons in the primary somatosensory cortex of euploid (black bar) and Ts65Dn mice (white bar). b Graph showing the density of calretinin-immunoreactive interneurons in every layer of the primary somatosensory cortex in euploid and Ts65Dn mice. Field survey of the somatosensory cortex of a control (c) or a Ts65Dn (d) showing the distribution of calretinin-immunoreactive interneurons. Scale bar $200 \mu \mathrm{m}$ $(* P<0.05 ; * * P<0.01$; $* * * P<0.001)$
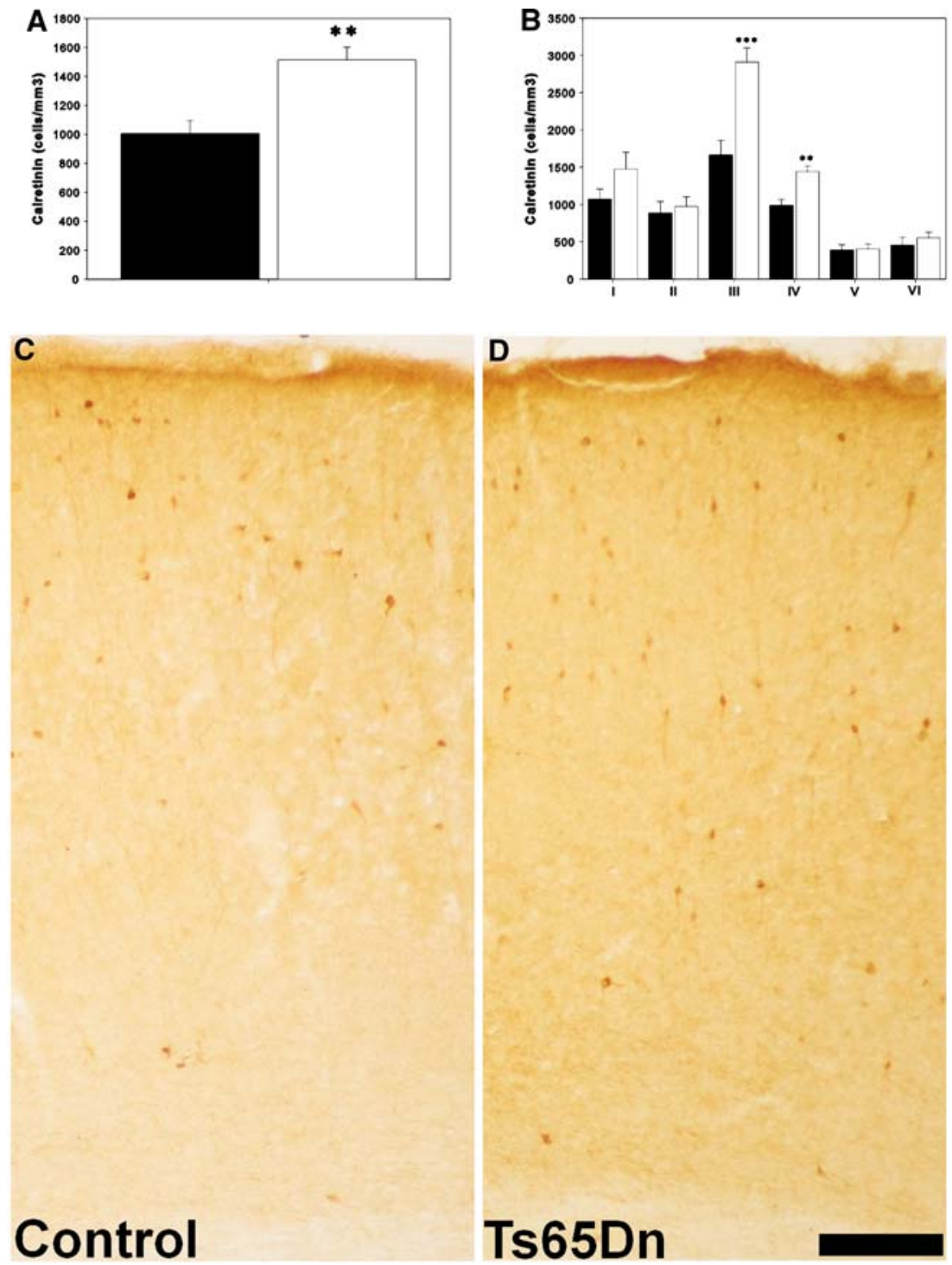

ventricular zone (Letinic et al. 2002). The density of interneurons expressing calretinin appears to be developmentally regulated in rodents, reaching a peak during the first postnatal days and declining thereafter (Schierle et al. 1997), although most of these cells expressing transitorily calretinin should be principal cells. In this context, newly born cells in mice express transiently calretinin.

Another model in which calretinin-immunoreactive neurons are overexpressed is in animals under early ethanol exposure (Granato 2006). This early exposure to ethanol may prevent the reduction of calretinin elements. Something similar could happen in the Down's syndrome model. In the same line of evidence, alterations in the distribution of calretinin neurons, reflecting heterotopias caused by migrational defects, have been observed in organotypic cortical cultures treated with ethanol (Mooney et al. 2004).

Calretinin-expressing cells are not homogeneous (Meskenaite 1997; Rogers 1992; Rogers and Resibois
1992). They include the Cajal-Retzius cells of layer I, bipolar interneurons (elongated soma with one of two dendrites oriented vertically) and multipolar interneurons (round cell bodies with multiple primary dendrites) (Conde et al. 1994; Gabbott and Bacon 1996; Meskenaite 1997; Caputi et al. 2009). It seems that Cajal-Retzius cells are unaltered since the fact that calretinin-immunoreactive neurons in layer I remain unaltered in Ts65Dn. The other two populations of calretinin-immunoreactive interneurons, i.e. the one with bipolar morphology $(\mathrm{BCR})$ and the other with multipolar morphology (MCR) are affected in Ts65Dn. The densities of both types were increased in the primary somatosensory cortex of Ts65Dn mice. This increment is mainly located in layer III. However, the subpopulation of BCR was more affected than the one of MCR. Functionally, MCR cells seem to be involved in the maintenance of rhythmic activity (theta frequency oscillations), and BCR cells act as "disinhibitory" cells relieving 
Fig. 6 Alterations in the density and distribution of different morphological population of calretininimmunoreactive interneurons (CR IR) in the somatosensory cortex of Ts65Dn mice. a Image of a Bipolar cell (BCR). b Image of a Multipolar cell (MCR). c Graph showing the total density of BCR

interneurons in the primary somatosensory cortex of euploid (black bar) and Ts65Dn mice (white bar). d Graph showing the total density of MCR interneurons in the primary somatosensory cortex of euploid and Ts65Dn mice. e Graph showing the density of BCR interneurons in every layer of the primary somatosensory cortex in euploid and Ts65Dn mice. f Graph showing the density of MCR interneurons in every layer of the primary somatosensory cortex in euploid and Ts65Dn mice. Scale bar $25 \mu \mathrm{m}(* P<0.05 ; * * P<0.01$; $* * * P<0.001)$
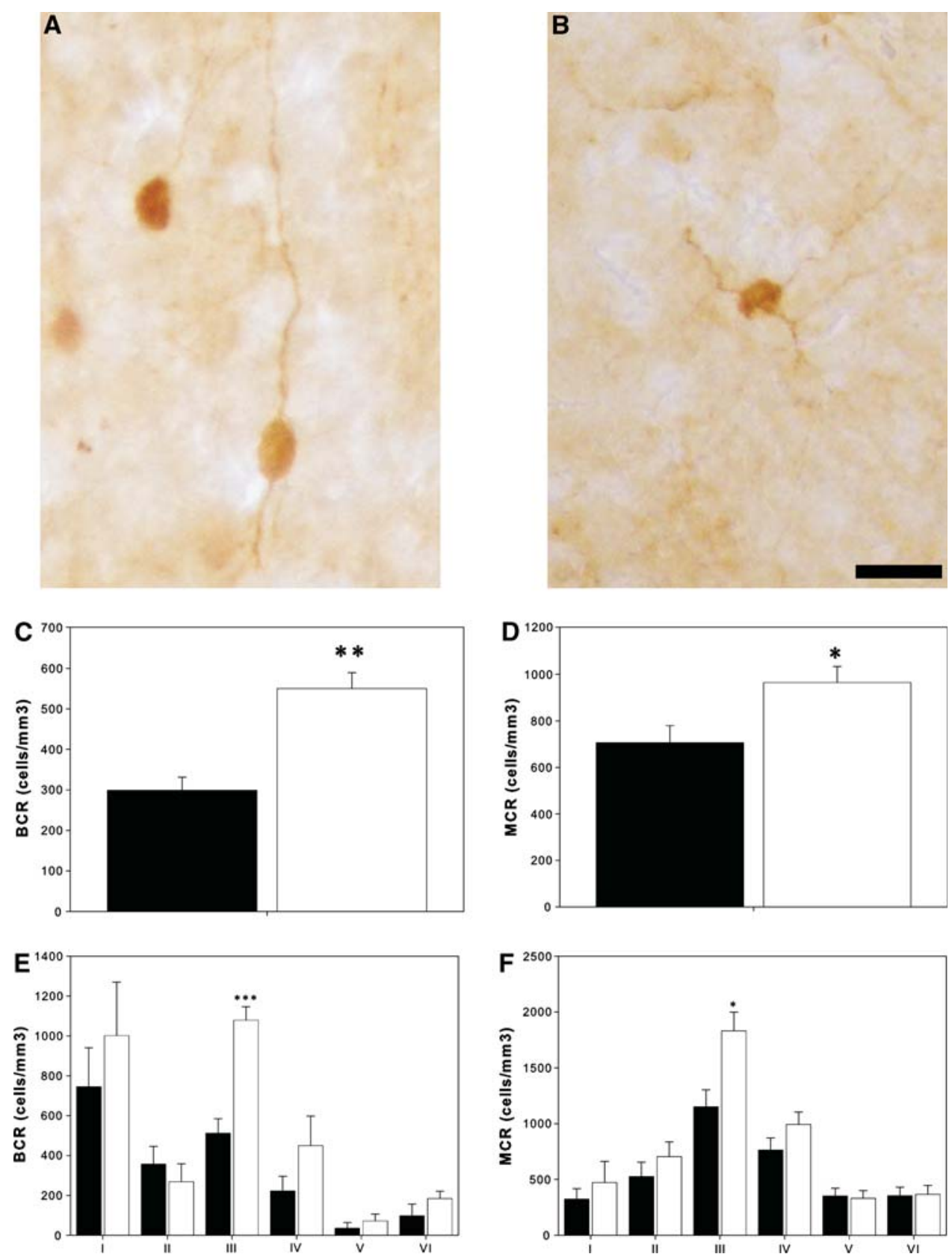

layer 2/3 pyramidal cells from inhibition (Caputi et al. 2009). BCR cells in the neocortex are interneuron-selective (IS) cells and seem to target specifically other interneurons (Gonchar and Burkhalter 1999).

The increase in the density of total inhibitory neurons in the somatosensory cortex could reveal a higher level of inhibition. Previous studies have pointed a higher level of inhibition in some regions of the neocortex and the hippocampus (Belichenko et al. 2004, 2007, 2009; Kurt et al. 2000). In this sense, treatment with picrotoxin $\left(\mathrm{a} \mathrm{GABA}_{\mathrm{A}}\right.$ receptor antagonist), improves behavioural performance (Fernandez et al. 2007). Our study goes deeper analysing the different subpopulations of interneurons. Different types of interneurons display different roles in the cortex.

Parvalbumin-immunoreactive interneurons are fast spiking cells that are divided into two main types of interneurons: chandelier cells (that connect with principal neurons in the initial segment of the axon) and basket cells that make perisomatic inhibition. They control mainly network synchronisation.

MCR and calbindin D-28k interneurons are regular spiking cells involved in the control of the signalling on principal cells and signal integration (Cauli et al. 1997; Markram et al. 2004). 
BRC neurons inhibit other interneurons producing as a final result the disinhibition of the system. They are feedforward activated by the same inputs that activate the principal cells and seem able to control the function of the other interneurons. However, not all types of interneurons are equally innervated by them.

Therefore, the neuronal inhibition is a complex process that cannot be reduced to simply the opposite of excitation. For this reason the separated study of the different subpopulations in every area is necessary to fully understand the inhibitory balance.

Then, although it would be tempting to interpret this increment of interneurons as an increase of inhibition in patients with Down's syndrome, the high susceptibility to epilepsy that they present (Stafstrom 1993) indicates rather the contrary. Epilepsy has been related to the alteration in the balance between excitation and inhibition. The increment in interneurons could reflect an attempt by the system to cope with the overexcitation.

This hypothesis could support the discrepancies of the results obtained in the cortex of elderly patients suffering Down's syndrome. A reduction in the number of total interneurons (Ross et al. 1984) and more specifically in the number of calbindin D-28k and parvalbumin interneurons (Kobayashi et al. 1990) has been observed. This overall overexcitation in DS could be reflected as an increase in the number of interneurons in young adult animals, but could lead to excitotoxicity with the result of increased neuronal death during ageing affecting both interneurons and principal cells.

The study of the alterations in the different types of inhibition in DS can shed light on the processes leading to the neurological deficits and can help to design novel strategies to contain the mental retardation associated with this disorder.

Acknowledgments This study was funded by Spanish Ministry of Education and Science (BFU2006-07313/BFI and BFU2007-64130/ BFI); Foundation Jerome Lejeune and The Stanley Medical Research Institute (08R-2007).

\section{References}

Anderson SA, Kaznowski CE, Horn C, Rubenstein JL, McConnell SK (2002) Distinct origins of neocortical projection neurons and interneurons in vivo. Cereb Cortex 12:702-709

Becker LE, Armstrong DL, Chan F (1986) Dendritic atrophy in children with Down's syndrome. Ann Neurol 20:520-526

Belichenko PV, Masliah E, Kleschevnikov AM, Villar AJ, Epstein CJ, Salehi A, Mobley WC (2004) Synaptic structural abnormalities in the Ts65Dn mouse model of Down syndrome. J Comp Neurol 480(3):281-298

Belichenko PV, Kleschevnikov AM, Salehi A, Epstein CJ, Mobley WC (2007) Synaptic and cognitive abnormalities in mouse models of Down syndrome: exploring genotype-phenotype relationship. J Comp Neurol 504:329-345

Belichenko PV, Kleschevnikov AM, Masliah E, Wu C, Takimotokimura R, Salehi A, Mobley W (2009) Excitatory-inhibitory relationship in the fascia dentate in the Ts65Dn mouse model of Down syndrome. J Comp Neurol 512:453-466

Berbel P, Marco P, Cerezo JR, DeFelipe J (1996) Distribution of parvalbumin immunoreactivity in the neocortex of hypothyroid adult rats. Neurosci Lett 204:65-68

Caputi A, Rozov A, Blatow M, Monyer H (2009) Two calretininpositive GABAergic cell types in layer $2 / 3$ of the mouse neocortex provide different forms of inhibition. Cereb Cortex 19:1345-1359

Cauli B, Audinat E, Lambolez B, Angulo MC, Ropert N, Tsuzuki K, Hestrin S, Rossier J (1997) Molecular and physiological diversity of cortical nonpyramidal cells. J Neurosci 17(10):3894-3906

Conde F, Lund JS, Jacobowitz DM, Baimbridge KG, Lewis DA (1994) Local circuit neurons immunoreactive for calretinin, calbindin D-28k or parvalbumin in monkey prefrontal cortex: distribution and morphology. J Comp Neurol 341:95-116

Costa AC, Walsh K, Davisson MT (1999) Motor dysfunction in a mouse model for Down syndrome. Physiol Behav 68:211-220

Dierssen M, Ramakers GJ (2006) Dendritic pathology in mental retardation from molecular genetics to neurobiology. Genes Brain Behav 5(Suppl 2):48-60

Dierssen M, Benavides-Piccione R, Martinez-Cue C, Estivill X, Florez J, Elston GN, DeFelipe J (2003) Alterations of neocortical pyramidal cell phenotype in the Ts65Dn mouse model of Down syndrome: effects of environmental enrichment. Cereb Cortex 13:758-764

Eastwood SL, Harrison PJ (2001) Synaptic pathology in the anterior cingulated cortex in schizophrenia and mood disorders: a review and a Western blot study of synaptophysin, Gap-43 and the complexins. Brain Res Bull 55:569-578

Escorihuela RM, Fernández-Teruel A, Vallina IF, Baamonde C, Lumbreras MA, Dierssen M, Tobeña A, Florez J (1995) A behavioural assessment of Ts65Dn mice: a putative Down syndrome model. Neurosci Lett 199:143-146

Escorihuela RM, Vallina IF, Martinez-Cue C, Baamonde C, Dierssen M, Tobeña A, Florez J, Fernández-Teruel A (1998) Impaired short- and long-term memory in Ts65Dn mice, a model for Down syndrome. Neurosci Lett 247:171-174

Fernandez F, Morishita W, Zuniga E, Nguyen J, Blank M, Malenka RC, Garner CC (2007) Pharmacotherapy for cognitive impairment in a mouse model of Down syndrome. Nat Neurosci 10:411-413

Foldy C, Aradi I, Howard A, Soltesz I (2004) Diversity beyond variance: modulation of firing rates and network coherence by GABAergic subpopulations. Eur J Neurosci 19:119-130

Gabbott PL, Bacon SJ (1996) Local circuit neurons in the medial prefrontal cortex in the monkey: II, quantitative areal and laminar distributions. J Comp Neurol 364:609-636

Gardiner K, Fortna A, Bechtel L, Davisson MT (2003) Mouse models of Down syndrome: how useful can they be? Comparison of the gene content of human chromosome 21 with orthologous mouse genomic regions. Gene 318:137-147

Gonchar Y, Burkhalter A (1999) Connectivity of GABAergic calretinin immunoreactive neurons in rat primary visual cortex. Cereb Cortex 9:683-696

Granato A (2006) Altered organization of cortical interneurons in rats exposed to ethanol during neonatal life. Brain Res 1069:23-30

Holtzman DM, Santucci D, Kilbridge J, Chua-Couzens J, Fontana DJ, Daniels SE, Johnson RM, Chen K, Sun Y, Carlson E, Alleva E, Epstein CJ, Mobley WC (1996) Developmental abnormalities 
and age-related neurodegeneration in a mouse model of Down syndrome. Proc Natl Acad Sci USA 96:13333-13338

Hunter CL, Bachman D, Granholm AC (2004) Minocycline prevents cholinergic loss in a mouse model of Down's syndrome. Ann Neurol 56:675-688

Kaufmann WE, Moser HW (2000) Dendritic anomalies in disorders associated with mental retardation. Cereb Cortex 10:981-991

Kobayashi K, Emson PC, Mountjoy CQ, Thornton SN, Lawson DE, Mann DM (1990) Cerebral cortical calbindin D28K and parvalbumin neurones in Down's syndrome. Neurosci Lett 113:17-22

Kurt MA, Davies DC, Kidd M, Dierssen M, Florez J (2000) Synaptic deficit in the temporal cortex of partial trisomy 16 (Ts65Dn) mice. Brain Res 858:191-197

Letinic K, Zoncu R, Rakic P (2002) Origin of GABAergic neurons in the human neocortex. Nature 417:645-649

Marin-Padilla M (1976) Pyramidal cell abnormalities in the motor cortex of a child with Down's syndrome: a Golgi study. J Comp Neurol 167:63-81

Markram H, Toledo-Rodriguez M, Wang Y, Gupta A, Silberberg G, Wu C (2004) Interneurons of the neocortical inhibitory system. Nat Rev Neurosci 5:793-807

Masliah E, Terry RD, Alford M, DeTeresa R (1990) Quantitative immunohistochemistry of synaptophysin in human neocortex: an alternative method to estimate density of presynaptic terminals in paraffin sections. J Histochem Cytochem 38:837-844

Meskenaite V (1997) Calretinin-immunoreactive local circuit neurons in area 17 of the cynomolgus monkey, Macaca fascicularis. J Comp Neurol 379:113-132

Mooney SM, Siegenthaler JA, Miller MW (2004) Ethanol induces heterotopias in organotypic cultures of rat cerebral cortex. Cereb Cortex 14:1071-1080

Reeves RH, Irving NG, Moran TH, Wohn A, Kitt C, Sisodia SS, Schmidt C, Bronson RT, Davisson MT (1995) A mouse model for Down syndrome exhibits learning and behaviour deficits. Nat Genet 11:177-184

Rogers JH (1992) Immunohistochemical markers in the rat cortex: colocalization of calretinin and calbindin-D28k with neuropeptides and GABA. Brain Res 587:147-157
Rogers JH, Resibois A (1992) Calretinin and calbindin-D28k in rat brain: patterns of partial co-localization. Neuroscience 51:843865

Roizen NJ, Patterson D (2003) Down's syndrome. Lancet 361:12811289

Ross MH, Galaburda AM, Kempre TL (1984) Down's syndrome: is there a decreased population of neurons? Neurology 34:909-916

Schierle GS, Gander JC, D'Orlando C, Ceilo MR, Vogt Weisenhorn DM (1997) Calretinin-immunoreactivity during postnatal development of the rat isocortex: a qualitative and quantitative study. Cereb Cortex 7:130-142

Stafstrom CE (1993) Epilepys in Down syndrome: clinical aspects and possible mechanisms. Am J Ment Retard 98 Suppl:12-26

Takashima S, Becker LE, Armstrong DL, Chan F (1981) Abnormal neuronal development in the visual cortex of the human fetus and infant with down's syndrome: a quantitative and qualitative Golgi study. Brain Res 225:1-21

Takashima S, Ieshima A, Nakamura H, Becker LE (1989). Dendrites, dementia and the Down syndrome

Varea E, Blasco-Ibáñez JM, Gómez-Climent MA, Castillo-Gómez E, Crespo C, Martínez-Guijarro FJ, Nácher J (2007) Chronic fluoxetine treatment increases the expression of PSA-NCAM in the medial prefrontal cortex. Neuropsychopharmacology 32(4):803-812

Vuksic M, Petanjek Z, Rasin MR, Kostovic I (2002) Perinatal growth of prefrontal layer III pyramids in Down syndrome. Pediatr Neurol 27:36-38

Wichterle H, Turnbull DH, Nery S, Fishell G, Alvarez-Buylla A (2001) In utero fate mapping reveals distinct migratory pathways and fates of neurons born in the mammalian basal forebrain. Development 128:3759-3771

Xu Q, de la Cruz E, Anderson SA (2003) Cortical interneuron fate determination: diverse source for distinct subtypes? Cereb Cortex 13:670-676 